Mariângela Aparecida Rezende

Aleixo ${ }^{1}$

(D) https://orcid.org/0000-0003-3533-680X

Margarete Borges de Borges

o hitps://orid.orgy/0000.0002.9580.2289

Bruno Rabinovici Gherman’

Ohttps://orcid.org/0000-0001-8208-3273

Ivan Abdala Teixeira'

(1) https://orcid.org/0000-0003-0011-0034

José Pedro Simões Neto ${ }^{2}$

(1) https://orcid.org/0000-0001-6322-2389

Raquel Luiza Santos ${ }^{1}$

O https://orcid.org/0000-0001-7460-901X

Marcia Cristina Nascimento

Dourado ${ }^{1}$

(- https://orcid.org/0000-0001-6267-8202

Valeska Marinho'

(1) https://orcid.org/0000-0003-4665-9655

\section{Active music therapy in dementia: results from an open-label trial}

\author{
Musicoterapia ativa na demência: resultados de um estudo aberto
}

DOl: 10.1590/0047-2085000000363

\begin{abstract}
Objective: Cognitive, neuropsychiatric and functional deficits are core symptoms of dementia. Non-pharmacological interventions, such as music therapy, when used in conjunction with pharmacological treatment, have the potential to alleviate these symptoms. The purpose of this preliminary study is to examine the active music therapy on cognition and neuropsychiatric symptoms in the elderly with mild and moderate dementia. Methods: The initial sample consisted of outpatients with dementia ( $N$ $=15)$ and their family members or caregivers $(N=15)$. Two dyads did not complete the assessments before intervention and were excluded from the analysis. Thirteen females $(N=13)$ comprised the final sampled and were diagnosed with Alzheimer's disease $(N=10)$, vascular dementia $(N=2)$ and mixed dementia $(N=1)$, at mild $(N=11)$ and moderate $(N=2)$ dementia stage. Participants were enrolled in an open-label trial of active music therapy group, set to take place once weekly for 60 minutes over a period of 12 weeks. Results: Participants experienced a slight improvement on cognition measured with Mini-Mental State Examination $(p=0.41)$, although without statistical significance and a statistically significant decrease in anxiety $(p=0.042)$ in post-intervention. There were no significant effects on quality of life and caregiver burden. Conclusions: Active music therapy is a promising intervention with good acceptance among participants. More studies with larger sample sizes are needed to confirm its effects and efficacy in cognitive and neuropsychiatric symptoms in dementia.
\end{abstract}

\section{KEYWORDS}

Music therapy, dementia, Alzheimer's disease, neuropsychiatric symptoms, cognition.

\section{RESUMO}

Objetivo: Distúrbios cognitivos, comportamentais e funcionais são sintomas nucleares na demência. Intervenções não farmacológicas, como a musicoterapia, quando usadas em conjunto com o tratamento farmacológico, têm o potencial de aliviar esses sintomas. O objetivo deste estudo preliminar é examinar a musicoterapia ativa na cognição e nos sintomas neuropsiquiátricos em idosos com demência leve e moderada. Métodos: A amostra inicial foi composta por pacientes ambulatoriais com demência ( $N=15)$ e seus familiares ou cuidadores $(N=15)$. Duas duplas não completaram as avaliações antes da intervenção e foram excluídas da análise. Treze mulheres ( $N=13)$ compuseram a amostra final e foram diagnosticadas com doença de Alzheimer $(N=10)$, demência vascular $(N=2)$ e demência mista $(N=1)$, nos estágios leve $(N=11)$ e moderado $(N=2)$. Os participantes foram inscritos em um estudo aberto de grupo de musicoterapia ativa, programado para ocorrer uma vez por semana, com duração de 60 minutos, durante o período de 12 semanas. Resultados: Os participantes experimentaram uma discreta melhora cognitiva medida pelo Miniexame do Estado Mental $(p=0.41)$, embora sem significância estatística, e uma diminuição estatisticamente significativa na ansiedade ( $p=0.042)$ na pós-intervenção. Não houve efeitos significativos na qualidade de vida e sobrecarga do cuidador. Conclusões: A musicoterapia ativa é uma intervenção promissora, com boa aceitação entre os participantes. Mais estudos com amostras maiores são necessários para confirmar seus efeitos e eficácia em sintomas cognitivos e neuropsiquiátricos na demência.

\section{PALAVRAS-CHAVE}

Musicoterapia, demência, doença de Alzheimer, sintomas neuropsiquiátricos, cognição.
Received in: May/25/2021. Approved in: Dec/3/2021

1 Center for Alzheimer's Disease and Related Disorders, Institute of Psychiatry, Federal University of Rio de Janeiro (UFRJ), Rio de Janeiro, RJ, Brazil. 2 Department of Political Sociology, Federal University of Santa Catarina (UFSC), Florianópolis, SC, Brazil.

Address for correspondence: maraleixo@gmail.com, m.bborges@terra.com.br 


\section{INTRODUCTION}

Dementia is a term for diseases characterized by the development of multiple cognitive, behavioral and functional deficits', including Alzheimer's disease (AD), vascular dementia $(\mathrm{VaD})$, mixed dementia (MD)², and leading to distress for people with dementia and their caregivers ${ }^{3}$. The consequences of dementia on function and autonomy are devastating, as are the behavioral changes frequently present with disease progression. ${ }^{4}$ The progressive memory decline is accompanied by other cognitive impairments such as language, attention, orientation, judgment, and planning ${ }^{2}$. Neuropsychiatric symptoms (NPS) are defined by a set of symptoms such as agitation, aggression, irritability, depression, anxiety, apathy, behavior disorders, sleep disturbances, delusions and hallucinations ${ }^{4-7}$. These symptoms occur in 80\%-90\% of people with dementia (PwD) during the course of the disease ${ }^{7}$. Advances in pharmacological knowledge have enabled disease stabilization and brought improvements to cognitive symptomatology ${ }^{4}$. However, the efficacy of antidementia medications on behavioral symptoms is limited. Additionally, recent concerns about psychotropic drug use, such as antipsychotics, for the behavioral manifestations in dementia have precluded its use as a first-line treatment for such symptoms ${ }^{8,9}$. Non-pharmacological or psychosocial interventions are considered in many guidelines as the first option for managing disruptive behaviors in dementia. They are recommended as an initial strategy for behavioral disorders and functional decline and play an important role in delaying the progression of dementia ${ }^{10-12}$.

Non-pharmacological interventions aim at improving cognition, decreasing NPS, expressing emotions, socializing, and offering guidance to caregivers. Currently, available information has shown that psychosocial and sensory stimulation interventions may be useful to improve or maintain cognition, functionality, behavior and quality of life (QoL) $)^{10-12}$. Recent research points out that such interventions may benefit PwD and their caregivers ${ }^{13}$. However, the difficulty of standardizing the interventions and the outcomes for which they are designed limits their incorporation into clinical practice.

Different studies and clinical trials have used psychosocial interventions in dementia based upon music activities over the last decades ${ }^{14}$. Music therapy (MT) should not be mistaken for the generalized use of music. Music therapists use music and/or its parameters (sound, rhythm, mode, melody, harmony) to stimulate cognitive functions and social or emotional well-being; and reduce anxiety, agitation and depression ${ }^{14}$. In MT, music is focused on musical experience through improvisation, a re-creation of music (singing a familiar song and recreating it by changing the rhythm or lyrics), composition, playing musical instruments and music listening that can be applied together or separately ${ }^{15,16}$.
MT encompasses active or/interactive and receptive techniques. Active MT (AMT) requires the engagement of both participant and music therapist who interact actively in the process of making music (sound-producing, singing, dance-like movement, or playing instruments) ${ }^{15-22}$. MT interventions are characterized by the presence of a qualified music therapist, who can use applicable models based on psychological and/or rehabilitative approaches ${ }^{18}$. Cognitive aspects (memory, attention, perception, and others), reminiscence, communication, executive functions, creativity, and social interaction may be stimulated by these approaches ${ }^{23,24}$. Singing in a group setting can improve social skills and communication ${ }^{24}$.

Studies have pointed out the benefits of MT interventions in cognition and NPS in dementia ${ }^{18-22,25-41}$. Previous research, including randomized 19,21,28-31,34,37 or non-randomized, $_{1}$ 25,32-33,35,36,38-40 individual| $19,29,33,34$ and group trials, ${ }^{21,25,28,30-32,35-40}$ active $e^{19,21,25,28-32,35-40}$ or receptive ${ }^{19,33,34,37}$ intervention, with participation of the caregivers ${ }^{39,40}$, as well as narrative ${ }^{20}$ and systematic $22,26,27,41$ reviews suggest the benefits of MT intervention on cognition $20,27,28,41$, NPS 18,21,27-29,31,32,34,3,3,37-40 and Qol $17,39,40$. Some studies exploring the benefits and efficacy of MT interventions among PwD are focused on depression 18,28,32,34, or anxiety ${ }^{18,32,35}$. Besides, there is evidence reported by some clinical trials $s^{28,31,32,35,37-40}$, that active participation in group sessions of MT can give some meaning to the lives of PwD who have memory and behavioral disturbances. Conversely, other studies showed no evidence of improvement in behavior ${ }^{30,36}$, quality of life, long term and short-term depression ${ }^{27}$, and in cognition ${ }^{22}$. Recent studies focused on therapeutic group singing ${ }^{39}$ and songwriting ${ }^{40}$ suggested a positive impact of MT on PwD depression and caregivers' QoL. A systematic review and meta-analysis study ${ }^{41}$ found evidence of a beneficial effect of AMT on global cognition on PwD.

In this context, the purpose of this preliminary study is to examine the effects of active MT technique on cognition and NPS in the elderly with mild and moderate dementia.

\section{METHODS}

\section{Participants}

The sample consisted of outpatients of the Center for Alzheimer's Disease and Related Disorders (CDA) of the Institute of Psychiatry of the Federal University of Rio de Janeiro (IPUB-UFRJ) and their family members or caregivers.

Inclusion criteria: Eligibility criteria for participants: a) a diagnosis of probable or possible dementia in mild or moderate stage; b) age schooling $\geq 4$ years; c) age $\geq 60$ years. Eligibility criteria for caregivers: a) familiar or not; b) age schooling $\geq 4$ years; $\mathrm{c}$ ) age $\geq 18$ years. PwD and caregivers needed to have functional hearing (with or without aids). The flowchart of the study design is shown in figure 1. 


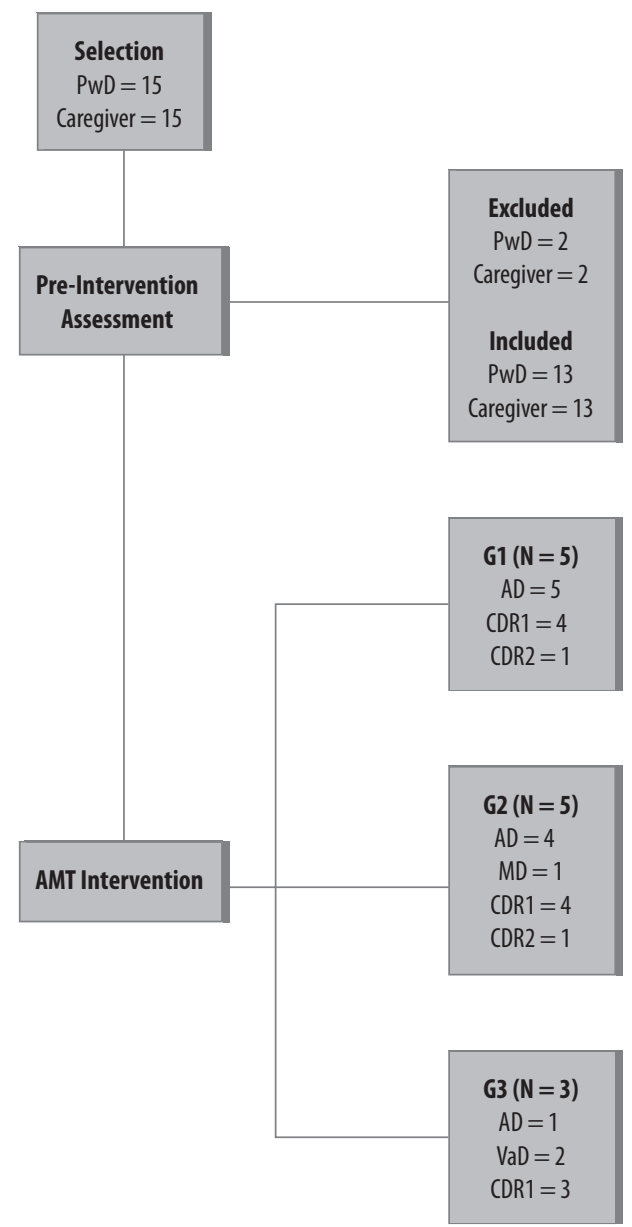

Figure 1. Flow chart of study design.

PwD: People with Dementia; AMT: Active Music Therapy; G: Group; AD: Alzheimer's Disease; VaD: Vascular Dementia; MD: Mixed Dementia; CDR: Clinical Dementia Rating.

\section{Instruments}

\section{Clinical Dementia Rating $(C D R)^{42,43}$}

The CDR is used to characterize six domains of cognitive and functional performance applicable to Alzheimer's disease and related dementias: memory, orientation, judgment and problem solving, community affairs, home and hobbies, and personal care. It is a 5-point scale in which CDR-0 connotes no cognitive impairment, CDR-0.5 = very mild dementia, CDR-1 = mild, CDR-2 = moderate, CDR-3 = severe

\section{Mini-Mental State Examination (MMSE) ${ }^{44,45}$}

The MMSE assesses cognitive ability within a wide range of domains, including calculation, memory, language, and orientation. Its maximum score is 30 and can be influenced by the individual's educational background. Brazilian cutoff scores usually consider a score below 26 as indicating cognitive impairment for individuals with high educational background; 18 points for those with low/medium educational background, and 13 points for illiterates ${ }^{45}$. A score below 23 on the MMSE generally indicates cognitive impairment.

\section{Alzheimer's Disease Assessment Scale - cognitive subscale (ADAS-Cog) $)^{46,47}$}

ADAS-Cog is a sensitive test to detect cognitive changes over time and is designed to assess the cognitive symptoms associated with AD and other dementias. The ADAS-Cog consists of 11 items evaluating: orientation, memory (remembering words and instructions, recognition), language (ability and understanding of spoken language, difficulty finding words, naming and pointing objects, following instructions) and praxia (ideational and constructive). The total score of the 11 items ranges from 0 to 70. The ADAS-Cog takes 20-35 minutes to be conducted and classified. Higher scores indicate a poorer performance.

\section{Neuropsychiatric Inventory (NPI) ${ }^{48-50}$}

The NPI evaluates 12 common neuropsychiatric disturbances in dementia: delusions, hallucinations, agitation, dysphoria, anxiety, apathy, irritability, euphoria, disinhibition, aberrant motor behavior, night-time behavior disturbances, and appetite and eating abnormalities. The severity ( $1=$ mild, $2=$ moderate, 3 = severe) and frequency ( 1 = occasionally, less than once per week; 2 = often, about once per week; 3 = frequently, several times per week but less than every day; 4 = very frequently, once or more per day or continuously) of each neuropsychiatric symptom are rated on the basis of scripted questions given to the patient's caregiver. The total score of these 12 items varies from 0 to 144. Caregiver distress is rated by the caregiver on a six-point scale from 0 (no distress) to 5 (very severe or extreme distress).

\section{Quality of Life scale in Alzheimer's Disease (QoL-AD) for measuring quality of life in PwD (patient and caregiver versions) ${ }^{51,52}$}

Qol-AD features subjective and objective indicators. Objective indicators include living standards, chronic disease grade, interpersonal relationships with family and friends, and community resources. Subjective indicators are based on personal assessments of life satisfaction, happiness, food adequacy, financial resources, family relationships, and feelings of human beings as a whole. QoL-AD is an instrument consisting of thirteen items related to the quality of life of the elderly with dementia. We applied the patient's quality of life (QoL) as perceived by both the patient (QoL-P) and by the caregiver (QoL-C). The total score ranges from 13 (bad) to 52 (excellent).

\section{Zarit Burden Interview $(Z B I)^{53,54}$}

This scale is composed of 22 items and evaluates how care activities impact social life, physical and emotional wellbeing, and caregiver finances. The questions investigate the impact that the disease has on the caregiver. The answers to each item can be rated on a scale from 0 to 4 points: never (0), rarely (1), sometimes (2), often (3) and always (4). The scale 
was designed to be unmonitored but can also be conducted by an interviewer. In the latter case, the interviewer reads each item aloud and asks the respondent to point to the correct answer. Scores range from 0 to 88 with higher scores indicating higher level of burden.

\section{Alzheimer's Disease Cooperative Study - Clinical Global Impression of Change (ADCS-CGIC) ${ }^{55}$}

ADCS-CGIC is a semi-structured interview designed to evaluate clinically relevant changes in PwD. The ADCS-CGIC interview is guided by probing covering cognition, behavior, and daily and social functioning. The severity of symptoms is based on patients' and caregivers' responses. A global clinical judgment of severity at pre-intervention is used as a reference for subsequent scores of changes identified at each visit and ranges from 1 (normal, not ill) to 7 (extremely ill). At subsequent visits, an overall impression of change from 1 (marked improvement) to 7 (marked worsening) is ranked compared to pre-intervention. ADCS-CGIC can be administered by an experienced physician after a short training session. It takes approximately 30-45 minutes to apply. The ADCS-CGIC classifier should be blind to all other safety and efficacy assessments, except for the baseline classification (visit 2), where classifiers can have access to all patient information. The first interview is not scored.

All the assessments took place on dates and rooms separately from those where the intervention occurred. PwD ( $N=13)$ completed MMSE and ADAS-Cog assessments. Caregivers ( $N=13$ ) completed NPI and ZBI. The dyads ( $N=$ 13) completed QoL-AD and ADCS-CGIC assessments. PwD $(N=13)$ and caregivers $(N=13)$ completed assessments pre and post 12-week MT intervention.

\section{Music therapy intervention}

Participants were accompanied by their caregivers for study procedures. The AMT interventions were only applied to PwD. Three groups ( $N=5 ; N=5 ; N=3$ ) were formed and completed the 12-week AMT intervention at different timepoints during the study. The groups were heterogeneous regarding etiology and severity of dementia. The participants did not need to have musical or singing knowledge or to know how to play a musical instrument.

PwD attended the AMT group technique which was employed once weekly over a 12 weeks period in 60-minute sessions, in a specific room where there were different musical instruments and a computer for listening to favorite or familiar songs. The AMT intervention was delivered by a music therapist with PhD qualifications and more than 20 years of experience working in the dementia field. The music therapist also performed music therapeutic interviews and evaluations prior to the beginning of the intervention to collect data about PwD musical history (musical experience, musical and instrumental preference, favorite songs) and to observe participants' capacity to recognize melodies, reproduce songs and rhythm and discriminate timbre.

The interventions consisted of an initial part (5-10 minutes) with questions directed at each member of the group to know their status at that moment. The music therapist then invited the participants to sing familiar or favorite songs, play musical instruments and/or listen to songs without the help of headphones (40 minutes). The sessions were not pre-planned but, instead, adapted to desires, cognition and mood in the here-and-now. All activities were conducted to prioritize PwD initiative to sing, play or listen to music. AMT techniques (re-creation, improvisation, hearing and composition) were used in different moments. Musical re-creation experience was the most frequently used method. PwD were able to re-create familiar songs by singing, in conjunction with the use of musical instruments or not. Sometimes, lyric substitution was suggested using a known song to stimulate creative expression. At other times, a computer was used to play songs. In these moments, the participants listened to their favorite songs and other musical styles. During the intervention, a conversation about the action developed (playing, singing, listening) could happen, with memories of their life stories, associated with the family or other events (travel, party, dance). In these moments, PwD were invited to talk about the reminiscence and after to participate in a new musical production, such as choosing a song for that story (suggested by the PwD or music therapist) or reproducing the feeling by playing an instrument and making a sound. In the end, each member of the group was asked questions to know how they were feeling (10 minutes).

The purpose of the intervention is not the learning of a musical instrument or musical cognitive training. Each participant was invited to take part by using musical instruments, singing, dancing or making body movements. The sessions were tailored to meet the needs of all participants in the groups and offered a broad range of opportunities for expression and communication, aiming at enhancing expression of feelings, creativity development, cognitive stimulation, communication, and interpersonal relationship ${ }^{15,19,56}$.

\section{Statistical analysis}

All statistical analyses were performed with SPSS software version 22.0 for Windows. The sociodemographic and clinical characteristics (gender, age, schooling, duration and severity of illness, quality of life, cognition, functionality, NPS, caregivers' burden and clinical global impression) were analyzed with descriptive statistics. The Shapiro-Wilk test was used to verify normal data distribution. All variables except ADAS-Cog and NPI had normal distribution and were analyzed with paired Student's t-test. The Wilcoxon Test was used to analyze ADAS-Cog and NPI changes from pre to post 
intervention. The effect size (ES) was calculated to assess the magnitude of the effect of intervention ( $>0.20$ [small]; $>0.50$ [moderate]; 0.80 [large] $)^{57}$. The a-level was set at $P \leq 0.05$.

\section{Ethical issues}

This study was approved by the Ethics Committee of the Institute of Psychiatry of the Federal University of Rio de Janeiro, under the CAAE registry number 157410516.7.0000.5263. All the participants signed informed consent forms before any procedure. PwD were capable to consent and sign the document.

\section{RESULTS}

\section{Characteristics of the PwD and the caregivers}

The initial sample consisted of 15 outpatients (female $=13$, male $=2)$ and their family members or caregivers $(N=15)$. Two dyads ( $N=2$ ) of PwD and caregivers did not complete the assessments at the pre-intervention and were excluded from the analysis. The final sample was comprised by thirteen female PwD $(N=13)$, diagnosed with $A D(N=10), \operatorname{VaD}(N=$ 2) and $M D(N=1)$, at mild $(N=11)$ and moderate $(N=2)$ dementia stage according to the Clinical Dementia Rating $(C D R)^{42,43}$ (CDR-1 = mild or CDR-2 = moderate) and their family members or caregivers ( $N=13)$, who were invited to take part in this study.

The mean age of participants was $84(S D=3.16)$ with an average of 3.7 years of duration of disease $(S D=2.25)$. The mean age of caregivers was 55.9 years $(S D=11.70)$. The slight majority of the caregivers were female $(53.84 \% ; \mathrm{N}=7)$. Five were the daughters (38.5\%; $N=5)$, five were the sons (38.5\%; $N=5)$, one was the husband $(7.7 \% ; N=1)$, one was the sister $(7.7 \%, N=1)$, and one was the granddaughter $(7.7 \%, N=1)$.
The sociodemographic data of PwD and their caregivers is summarized in table 1.

\section{Comparison between the clinical characteristics at pre- and post-intervention}

Session attendance was high, $77 \%$ of participants $(N=10)$ attended 10 or more sessions with no dropouts during the procedures.

There was slight improvement on cognition measured by the MMSE ( $S D=2.87 ; 5.25$ ), although without statistical significance ( $p=0.41$ ) between pre- and post-intervention and the ES was small $(E S=0.18)$. The results also showed no improvement in cognition measured by the ADAS-Cog between pre- and post-intervention $(p=0.09)$ and the ES was also small ( $E S=0.31)$.

The NPI showed a numerical improvement that was not statistically significant difference between pre- and postintervention $(p=0.27)$. Additional analyses were performed to investigate NPI sub-item changes. Using the same statistical procedures, a statistically significant decrease in anxiety between pre-and post-intervention ( $p=0.042$ ) was found. We also verified a large ES only for anxiety $(E S=0.59)$ and for NPI total ( $E S=0.51)$. We also found a moderate ES for motor behavior ( $E S=0.31$ ). The other subdomains presented a small ES.

We did not find a significant difference in QoL-P measurements between pre-intervention and postintervention ( $p=0.69$ ). There was also no significant difference in QoL-C between pre-intervention and postintervention $(p=0.54)$.

There was not a significant difference in burden between pre-intervention and post-intervention $(p=0.17)$. The ES was small for QoL-P $(E S=0.08)$, QoL-C $(E S=0.08)$ and ZARIT (ES $=0.16)$.

Table 1. Characteristics of the PwD and the caregivers at pre-intervention

\begin{tabular}{|c|c|c|c|c|}
\hline \multirow{2}{*}{ Variable } & \multicolumn{2}{|c|}{ PwD (N = 13) } & \multicolumn{2}{|c|}{ Caregivers ( $N=13$ ) } \\
\hline & Mean (SD) & (\%) & Mean (SD) & (\%) \\
\hline Age & $84(3.16)$ & - & $55.9(11.70)$ & - \\
\hline Gendera,b & - & $13^{a}(100)$ & - & $7^{a} / 6^{b}(53.84 / 46.16)$ \\
\hline Schooling (4 years) & - & $2(15.40)$ & - & - \\
\hline Schooling (5-8 years) & - & $8(61.50)$ & - & - \\
\hline Schooling (>8 years) & - & $3(23.10)$ & - & $13(100 \%)$ \\
\hline Years since disease onset & 3.7 (2.25) & - & - & - \\
\hline$A D$ & - & $10(76.90)$ & - & - \\
\hline $\mathrm{VaD}$ & - & $2(15.40)$ & - & - \\
\hline MD & - & $1(7.70)$ & - & \\
\hline CDR1 & - & $11(84.60)$ & - & - \\
\hline CDR2 & - & $2(15.40)$ & - & - \\
\hline
\end{tabular}

a female; 'b male; AD: Alzheimer's Disease; VaD: Vascular Dementia; MD: Mixed Dementia; CDR: Clinical Dementia Rating. 
The PwD and the caregivers' clinical characteristics are summarized in table 2. NPI sub-item changes are summarized in table 3.

\section{Behavioral observation during intervention}

The type of dementia, clinical stage, and relationship with the caregiver may impact in different ways on MT intervention. In this study, AD participants who had a moderate (CDR2) rating before the intervention $(N=2)$ could participate actively, according to their possibilities at the time of each intervention. For example, a participant with moderate AD of Group 1 was active in singing and improvised a collective lyric about a well-known song, playing the instruments, and remembering her life's history. Conversely, a moderate $A D$ participant of Group 2 had difficulties developing a given activity but not participating in the group compared to the other participants and required active assistance by the music therapist. These observations demonstrate that the course of the disease is different for each PwD even when they are at the same stage of the disease

\section{DISCUSSION}

This open-label clinical trial consisted of a group intervention of AMT that involved producing sounds, singing favorite or familiar songs, and listening to them. Some attempts to substitute lyrics to a known song were made during the intervention. The chosen songs were based on the participants' personal tastes, which were ascertained at a preliminary interview. Group MT sessions were selected to encourage social interaction and enable and facilitate the expression of emotions and ideas. This type of intervention also enables the interaction between participants and the music therapist when singing and listening to known songs or playing musical instruments. The participants showed preserved musical memory of familiar and favorite songs, indicating the effect of this type of intervention for PwD. Several studies have shown that musical memory is well preserved in PwD until late stages of the disease ${ }^{58-60}$. These findings of previous studies provide important data that can improve the communication, the social interaction, and the

Table 2. Comparison between the clinical characteristics at pre- and post-intervention

\begin{tabular}{|c|c|c|c|}
\hline & \multicolumn{2}{|c|}{ Mean (SD) Score } & \multirow{2}{*}{$\frac{P}{T / X^{2}}$} \\
\hline & Pre-intervention $(\mathrm{N}=13)$ & Post-intervention ( $\mathrm{N}=13$ ) & \\
\hline MMSE & $16.38(2.87)$ & $17.15(5.25)$ & 0.41 \\
\hline ADAS-Cog ${ }^{\mathrm{a}}$ & $39(33-56)$ & $45(31-59)$ & 0.09 \\
\hline $\mathrm{NPI}^{\mathrm{a}}$ & $8(0-25)$ & $3(0-20)$ & 0.27 \\
\hline QoL-P & $34.84(6.26)$ & $35.30(4.51)$ & 0.69 \\
\hline QoL-C & $30.23(7.13)$ & $29.69(6.71)$ & 0.54 \\
\hline ZBI & 36.07 (18.05) & $39.15(19.77)$ & 0.17 \\
\hline
\end{tabular}

MMSE: Mini Mental State Exam; ADAS-Cog: Alzheimer's Disease Assessment Scale-Cognitive Subscale; NPI: Neuropsychiatric Inventory; QoL-P: Quality of Life scale in Alzheimer's Disease Patient; QoL-C: Quality of Life scale in Alzheimer's Disease Caregiver; ZBI: Zarit Burden Interview; X2: Wilcoxon Signed Ranks Test; ${ }^{a}$ median (range); $P \leq 0.05$.

Table 3. Comparison of NPI domains between pre-and post-intervention

\begin{tabular}{lcc}
\hline Domain & $\mathbf{Z}^{\mathrm{a}}$ & P value \\
\hline Hallucinations & .000 & 1.000 \\
Agitation/Aggression & -.447 & .655 \\
Dysphoria/Depression & -.406 & .684 \\
Anxiety & -2.032 & $.042^{*}$ \\
Euphoria/Elation & .000 & 1.000 \\
Apathy/Indifference & -.272 & .785 \\
Disinhibition & -1.342 & .180 \\
Irritability/Lability & -.447 & .655 \\
Aberrant Motor Behavior & -1.069 & .285 \\
Nighttime Behavioral Disturbances & -1.000 & .317 \\
Appetite/Eating Disturbances & .000 & 1.000 \\
Delusions & .000 & 1.000 \\
\hline
\end{tabular}

${ }^{a}$ Wilcoxon Signed Ranks Test. * Significant difference between pre-and post-intervention. 
quality of life of those who have lost their memory and other abilities. Previous research has also demonstrated that the group participants expressed positive feelings by singing familiar songs. Dassa and $\mathrm{Amir}^{25}$ showed that singing familiar songs helped to encourage conversation among people with $A D$ in moderate to late stage. The observations from this open label trial corroborate findings from previous studies about musical memory preservation and expression of positive feelings during AMT group participation.

Our study showed no improvement in cognition as measured with ADAS-Cog and MMSE. Considering MMSE, there was a slight improvement between pre-intervention (16.38) and post-intervention (17.15), with a non-statistical difference of 0.41 . The small sample size and open-label design may limit the generalizability of results and preclude firm conclusions in any direction. In systematic reviews and meta-analysis, Moreno-Morales et al. ${ }^{27}$ observed that listening to music and passive group intervention had a positive effect on cognitive function in PwD, while Fusar-Poli et al. ${ }^{41}$ showed evidence of a beneficial effect of AMT on global cognition. Chu et al..$^{28}$ carried out a randomized study with AMT group and reported significantly improved cognitive function.

The NPI scores at pre-intervention were low, with a nonsignificant decrease in post-intervention scores. Although there was no significant difference in the total score, there was an improvement in the anxiety outcome. In moderate and severe dementia MT groups, Raglio et al. ${ }^{31,35}$ showed a decrease in global NPI score at the end of the treatment ${ }^{31}$, and after 8 and 16 weeks ${ }^{35}$. Some studies showed decreased NPS $^{32,37,38}$, depression $28,32,34$ and anxiety ${ }^{34}$ in mild, moderate, and severe dementia MT groups, although the difference in baseline depression scores between the experimental and control groups was not significant ${ }^{28}$.

PwD can experience different levels of anxiety. This symptom that appears with decreased cognitive skills and day-to-day activities may decrease with MT interventions. According to Thaut ${ }^{61}$, music as mediating stimulus engages human behavior and brain function meaningfully by arousing, guiding, organizing, focusing, and modulating perception, attention, and behavior in the affective, cognitive, and sensorimotor domains. Randomized controlled studies as Guétin et al..$^{34}$ and Raglio et al..$^{35}$ showed the persistent effect of MT on symptoms of anxiety and depression for up to one or two months after the end of the sessions could be considered as the significant difference regarding other groups or activities.

Regarding the caregiver burden, it was observed that it was a group without high levels of burden, and it remained unchanged during and after the MT intervention. QoL-P and QoL-C scores did not show significant differences between pre-and post-intervention. Taking care of PwD can be exhaustive, mainly in the presence of NPS. As the care of PwD is usually provided by family members, the presence and intensity of NPS may have a direct impact on caregiver burden. The participants and their caregivers who agreed to participate in this weekly outpatient clinic intervention may be less predisposed to NPS at pre-intervention, as coming to the clinic weekly can be perceived as an additional burden.

This study adds an important piece of information regarding AMT's effect as a psychosocial intervention for PwD in Brazil. Many countries, including Brazil, recognize psychosocial interventions as an essential resource in taking care of PwD However, frequency, type of intervention and methodology for each psychosocial intervention designed to address PwD needs are still lacking in Brazil.

There are some limitations in this study that should be considered. The small sample of participants, different etiologies, and severity of dementia might impact the results. As the NPI is a measure mainly derived from caregivers' perspective, possible expectation bias should be considered. As participants had the opportunity to join an activity tailored to fulfill gaps in dementia care, expectations about positive results were high. Further studies with a larger sample size should analyze the effectiveness of MT on each neuropsychiatric symptom. Also, as there is no control group, the results should be interpreted with caution. Randomized controlled clinical trials using larger samples are needed to draw firm conclusions about AMT effectiveness for PwD in Brazil.

The intervention was easily implemented and not costly. However, we did not include a cost analysis and this would be important to include in a future study. The material used is readily available (computer and some rhythmic-melodic instruments) and the room required no previous adjustment. The high attendance rates also suggest good acceptability. The study results demonstrated that the project was technically and financially feasible.

\section{CONCLUSION}

Active music therapy is a promising intervention with good acceptance among participants. Adequately powered studies in more generalizable settings are needed to confirm its effects and efficacy in cognitive and behavioral symptoms in dementia.

\section{AUTHOR CONTRIBUTIONS}

All the authors drafted and critically revised the manuscript. All the authors approved the final version of the paper.

\section{AUTHOR DISCLOSURE STATEMENT}

No competing financial interests. 


\section{ACKNOWLEDGMENT}

Marcia Cristina Nascimento Dourado is a researcher 2 funded by the CNPq.

\section{REFERENCES}

1. American Psychiatric Association. Diagnostic and Statistical Manual of Mental Disorders. 5th ed. Arlington: American Psychiatric Association; 2013.

2. Caramelli P, Barbosa MT. Como diagnosticar as quatro causas mais frequentes de demência? Rev Bras Psiquiatr. 2002;24:7-10

3. Vega U, Marinho V, Tatsch M, Engelhardt E, Laks J. Transtornos de comportamento nas demências: descrição clínica, escalas de avaliação e considerações sobre seu tratamento. In: Bottino CMC, Laks J, Blay SL (Orgs.). Demência e transtornos cognitivos em idosos. Rio de Janeiro: Guanabara-Koogan; 2006. p. 314-21.

4. Lyketsos CG, Carrillo MC, Ryan JM, Khachaturian AS, Trzepacz P, Amatniek J, et al. Neuropsychiatric symptoms in Alzheimer's disease. Alzheimers Dement. 2011;7:532-9.

5. Lyketsos CG. Neuropsychiatric Symptoms in Dementia: Overview and Measurement Challenges. J Prev Alzheimers Dis. 2015;2:155-6.

6. Stella F. Assessment of neuropsychiatric symptoms in dementia: Toward improving accuracy. Dement Neuropsychol. 2013;7:244-51.

7. Bremenkamp MG, Rodrigues LR, Lage RR, Laks J, Cabral HWS, Morelato RL. Sintomas neuropsiquiátricos na doença de Alzheimer: frequência, correlação e ansiedade do cuidador. Rev Bras Geriatr Gerontol. 2014;17:763-73.

8. Nowrangi MA, Lyketsos CG, Rosenberg PB. Principles and management of neuropsychiatric symptoms in Alzheimer's dementia. Alzheimers Res Ther. 2015;7:12.

9. Seitz DP, Gill SS, Herrmann N, Brisbin S, Rapoport MJ, Rines J, et al. Pharmacological treatments for neuropsychiatric symptoms of dementia in long-term care: a systematic review. Int Psychogeriatr. 2013;25:185-203.

10. Zeisel J, Raia P. Nonpharmacological treatment for Alzheimer's disease: A mind-brain approach. Am J Alzheimers Dis 0ther Demen. 2000:15:331-40.

11. Bottino CMC, Carvalho IAM, Alvarez AMMA, Avila R, Zukauskas PR, Bustamante SEZ, et al. Reabilitação cognitiva em pacientes com doença de Alzheimer. Relato de Trabalho em equipe multidisciplinar. Arq Neuropsiquiatr. 2002;60:70-9.

12. Taveira RBR, Taveira DLR, Caixeta L. Abordagens não farmacológicas na doença de Alzheimer. In: Caixeta L, et cols. Doença de Alzheimer. Porto Alegre: Artmed; 2012. p. 353-67.

13. Livingston G, Kelly L, Lewis-Holmes E, Baio G, Morris S, Patel N, et al. A systematic review of the clinical effectiveness and cost-effectiveness of sensory, psychological and behavioural interventions for managing agitation in older adults with dementia. Health Technol Assess. 2014;18:1-226

14. Raglio A, Gianelli MV. Music Therapy for Individuals with Dementia: Areas of Interventions and Research Perspectives. Curr Alzheimer Res. 2009;6:293-301

15. Bruscia K. Definindo musicoterapia. $2^{\mathrm{a}}$ ed. Rio de Janeiro: Enelivros; 2000. 332p.

16. Barcellos LRM. Musicoterapia em medicina: uma tecnologia leve na promoção da saúde a dança nas poltronas! Rev Música Hodie. 2015;15:33-47.

17. Leggieri M, Thaut MH, Fornazzari L, Schweizer TA, Barfett J, Munoz DG, et al. Music intervention approaches for Alzheimer's disease: a review of the literature. Front Neurosci. 2019;13:132.

18. Raglio A, Stefania F, Bellandi D, Stramba-Badiale M. Global music approach to persons with dementia: evidence and practice. Clin Interv Aging. 2014;9:1669-76.

19. Raglio A, Bellandi D, Baiardi P, Gianotti M, Ubezio MC, Zanacchi E, et al. Effect of Active Music Therapy and Individualized Listening to Music on Dementia: A Multicenter Randomized Controlled Trial. J Am Geriatr Soc. 2015;63:1534-9.

20. Guetin S, Charras K, Berard A, Arbus C, Berthelon P, Blanc F, et al. An overview of the use of music therapy in the context of Alzheimer's disease: a report of a French expert group. Dementia (London). 2013;12:619-34.

21. Pigliautile M, Delicati F, Cecchetti R, Bastiani P, Scamosci M, Cesarini S, et al. Music therapy effects in People with Dementia. Sch J Psychol \& Behav Sci. 2019;2:134-47.
22. Lam HL, Li WTV, Laher I, Wong RY. Effects of Music Therapy on patients with dementia - A systematic review. Geriatrics. 2020;5:62.

23. Thaut MH. Neurologic Music Therapy in Cognitive Rehabilitation. Music Percept. 2010;27:281-5.

24. Pfeiffer CF, Sabe LR. Music therapy and cognitive rehabilitation: Screening of music cognition in adult patients with right hemisphere stroke. Psychomusicology. 2015;25:392-403

25. Dassa A, Amir D. The role of singing familiar songs in encouraging conversation among people with middle to late stage Alzheimer's disease. J Music Ther. 2014;51:131-53.

26. Aleixo MAR, Santos RL, Dourado MCN. Efficacy of music therapy in the neuropsychiatric symptoms of dementia: systematic review. J Bras Psiquiatr. 2017;66:52-61.

27. Moreno-Morales C, Calero R, Moreno-Morales P, Pintado C. Music Therapy in treatment of dementia: a systematic review and meta-analysis. Front Med. 2020;7:160.

28. Chu H, Yang CH, Lin Y, Ou KL, Lee TY, O'Brien AP, et al. The impact of group music therapy on depression and cognition in elderly persons with dementia: a randomized controlled study. Biol Res Nurs. 2014;16:209-17.

29. Ridder HMO, Stige B, Qvale LG, Gold C. Individual music therapy for agitation in dementia: an exploratory randomized controlled trial. Aging Ment Health. 2013;17:667-78.

30. Vink AC, Zuidersma M, Boersma F, de Jonge P, Zuidema SU, Slaets JPJ. The effect of music therapy compared with general recreational activities in reducing agitation in people with dementia: a randomized controlled trial. Int J Geriatr Psychiatry. 2013;28:1031-8.

31. Raglio A, Belleli G, Traficante D, Gianotti M, Ubezio MC, Gentile S, et al. Efficacy of music therapy treatment based on cycles of sessions: a randomized controlled trial. Aging Ment Health. 2010;14:900-4.

32. Han P, Kwan M, Chen D, Yusoff SZ, Chionh HL, Goh J, et al. A controlled naturalistic study on a weekly music therapy and activity program on disruptive and depressive behaviors in dementia. Dement Geriatr Cogn Disord. 2010;30:540-6.

33. Belgrave M. The effect of expressive and instrumental touch on the behavior states of older adults with late-stage dementia of the Alzheimer's type and on music therapist's perceived rapport. J Music Ther. 2009;46:132-46

34. Guétin S, Portet F, Picot MC, Pommié C, Messaoudi M, Djabelkir L, et al. Effect of music therapy on anxiety and depression in patients with Alzheimer's type dementia: randomized, controlled study. Dement Geriatr Cogn Disord. 2009;28:36-46.

35. Raglio A, Belleli G, Traficante D, Gianotti M, Ubezio MC, Villani D, et al. Efficacy of music therapy in the treatment of behavioral and psychiatric symptoms of dementia. Alzheimer Dis Assoc Disord. 2008;22:158-62.

36. Ledger AJ, Baker FA. An investigation of long-term effects of group music therapy on agitation levels of people with Alzheimer's disease. Aging Ment Health. 2007;11:330-8.

37. Svansdottir HB, Snaedal J. Music therapy in moderate and severe dementia of Alzheimer's type: a case control study. Int Psychogeriatr. 2006;18:613-21.

38. Tuet RWK, Lam LCW. A preliminary study of the effects of music therapy on agitation in Chinese patients with dementia. Hong Kong J Psychiatric. 2006;16:87-91.

39. Tamplin J, Clark IN, Lee YC, Baker FA. Remini-Sing: a feasibility study of therapeutic group singing to support relationship quality and wellbeing for community-dwelling people living with dementia and their family caregivers. Front Med. 2018;5:245.

40. Clark IN, Stretton-Smith PA, Baker FA, Lee YEC, Tamplin J. "It's feasible to write a song": a feasibility study examining group therapeutic songwriting for people living with dementia and their family caregivers. Front Psychol. 2020;11:1951

41. Fusar-Poli L, Bieleninik L, Biondino N, Chen XJ, Gold C. The effect of music therapy on cognitive functions in patients with dementia: a systematic review and meta-analysis. Aging Ment Health. 2018;22(9):1097-106.

42. Berg L. Clinical Dementia Rating (CDR). Psychopharmacol Bull. 1988;24:637-9.

43. Morris J. The Clinical Dementia Rating (CDR): current version and scoring rules. Neurology. 1993:43:2412-4.

44. Folstein MF, Folstein SE, McHugh PR. "Mini-mental state": A practical method for grading the cognitive state of patients for the clinician. J Psychiatr Res. 1975;12:189-98.

45. Bertolucci PH, Brucki SM, Campacci, SR, Juliano Y. 0 mini-exame do estado mental em uma população geral: impacto da escolaridade [The Mini-Mental State Examination in an outpatient population: Influence of literacy]. Arq Neuropsiquiatr. 1994;52:1-7.

46. Schultz RR, Siviero M0, Bertolucci PHF. The cognitive subscale of the "Alzheimer's Disease Assessment Scale" in a Brazilian sample. Braz J Med Biol Res. 2001;34:1295-302. 
47. Rosen WG, Mohs RC, Davis KL. ADAS-COG. A New Rating Scale for Alzheimer's Disease. Am J Psychiatry. 1984;141:1356-64.

48. Cummings JL, Mega M, Gray K, Rosenberg-Thompson S, Carusi DA, Gornbein J. The neuropsychiatric inventory: comprehensive assessment of psychopathology in dementia. Neurology. 1994;44:2308-14.

49. Cummings JL. The neuropsychiatric inventory: assessing psychopathology in dementia patients. Neurology. 1997;48:10-6.

50. Kaufer DI, Cummings JL, Christine D, Bray T, Castellon S, Masterman D, et al. Assessing the impact of neuropsychiatric symptoms in Alzheimer's disease: the Neuropsychiatric Inventory Caregiver Distress Scale. J Am Geriatr Soc. 1998;46:210-5.

51. Logsdon RG, Gibbons LE, McCurry SM, Teri L. Quality of life in Alzheimer's disease: patient and caregiver reports. J Ment Health Aging. 1999;5:21-32.

52. Novelli MMPC, Nitrini R, Caramelli P. Validation of the Brazilian version of the Quality of Life Scale for patients with Alzheimer disease and their Caregivers. Aging Ment Health. 2010;14:624-31.

53. Zarit SH, Reever KE, Bach-Peterson J. Relatives of impaired elderly: correlates of feeling of burden. Gerontologist. 1980;20:649-55.
54. Scazufca M. Brazilian version of the Burden Interview. Rev Bras Psiquiatr. 2002;24:12-7.

55. Ferris SH, Mackell JA, Mohs R, Schneider LS, Galasko D, Whitehouse PJ, et al. A multicenter evaluation of new treatment efficacy instruments for Alzheimer's disease clinical trials: overview and general results. The Alzheimer Disease Cooperative Study. Alzheimer Dis Assoc Disord. 1997;11:1-12.

56. Vink AC, Birks JS, Bruinsma MS, Scholten RJ. Music therapy for people with dementia. Cochrane Database Syst. Rev. 2003;(4):CD003477.

57. Cohen J. Statistical power analysis for the behavioral sciences. 2nd ed. Hillsdale, N.J.: L. Erlbaum Associates; 1988.

58. Crystal HA, Grober E, Masur D. Preservation of musical memory in Alzheimer's disease. J Neurol Neurosurg Psychiatry. 1989;52(12):1415-6.

59. Cuddy LL, Duffin J. Music, memory, and Alzheimer's disease: is music recognition spared in dementia, and how can it be assessed? Medi Hypotheses. 2005;64(2):229-35.

60. Vanstone AD, Cuddy LL. Musical memory in Alzheimer disease. Neuropsychol Dev Cogn B Aging Neuropsychol Cogn. 2010;17:108-28.

61. Thaut MH. The future of music in therapy and medicine. Ann N Y Acad Sci. 2005;1060:303-8. 